\title{
Unusual Rectal Foreign Body: A Golf Ball
}

\author{
Young Joo Park, Dong Hoon Baek, Eun Young Park, Gwang Ha Kim and Geun Am Song \\ Department of Internal Medicine, Pusan National University School of Medicine and Biomedical Research Institute, Pusan National \\ University Hospital, Busan, Korea
}

An 18-year-old man presented to the emergency department with a lower abdominal pain. He reported that his girlfriend had inserted a golf ball partially into his anus and lost it 6 hours earlier. The physical examination findings were unremarkable. The anus and surrounding area showed no signs of trauma. Plain pelvic/abdominal radiography revealed a 4.5$\mathrm{cm}$ round, opaque foreign body in the pelvic cavity (Fig. 1A). Contrast-enhanced abdominopelvic computed tomography revealed a $4.5-\mathrm{cm}$ spherical foreign body at the junction of the rectum and sigmoid colon; no perforation was found (Fig. 1B). The patient underwent proctosigmoidoscopy without sedation, which revealed a golf ball of $4 \mathrm{~cm}$ in diameter, approximately $15 \mathrm{~cm}$ from the anus. We initially used a Roth Net retriever (US Endoscopy, Mentor, OH, USA); however, the maximum width was only $3 \mathrm{~cm}$; therefore, we could not grasp the ball completely (Fig. 2A). The ball was finally extracted using a 30-mm stone extraction basket (The Web extraction basket; Cook Inc., Winston-Salem, NC, USA) and retrieved through the anus with the patient's cooperation (Fig. 2B, C). We found no mucosal defect or perforation after the removal of the ball through proctosigmoidoscopy. Two hours later, he was discharged after the absence of perforation was confirmed on chest and abdominal radiographs.

The incidence of rectal foreign bodies (RFBs) is not known precisely, but RFBs are encountered regularly in most large

\footnotetext{
Received: April 13, 2020 Revised: May 7, 2020

Accepted: May 7, 2020

Correspondence: Dong Hoon Baek

Department of Internal Medicine, Pusan National University School of Medicine and Biomedical Research Institute, Pusan National University Hospital, 179 Gudeok-ro, Seo-gu, Busan 49241, Korea

Tel: +82-51-240-7869, Fax: +82-51-244-8180, E-mail: dhbeak77@gmail.com ORCID: https://orcid.org/0000-0003-1512-9475

(c) This is an Open Access article distributed under the terms of the Creative Commons Attribution Non-Commercial License (http://creativecommons.org/ licenses/by-nc/3.0) which permits unrestricted non-commercial use, distribution, and reproduction in any medium, provided the original work is properly cited.
}

hospitals. RFBs are reported in all age groups, sexes, and races; however, more than two-thirds of patients are men aged 20 to 30 years. ${ }^{1}$ As the use of objects for sexual arousal increases, the number of hospital visits for removal of retained RFBs has increased. ${ }^{2}$ Most RFBs have been inserted deliberately by the patient or a sexual partner. Such foreign bodies are likely to be rounded/cylindrical shaped and smooth. The most frequently reported RFBs include bottles, followed by sexual devices, vegetables, fruits, and other household objects. RFB causes difficulties in extraction because several attempts have been made to extract it at home. A basic principle of management for a patient with a foreign body in the rectum is to avoid general anesthesia and laparotomy. Whether the object can be removed via the anus is determined by the shape, size, location, duration, and presence of perforation. RFBs may require a surgical approach if the following risk factors are present: hard or sharp objects, impaction of an object of $10 \mathrm{~cm}$ in length, migration of the object upward into the sigmoid colon, impaction of the object for $>2$ days, and presence of perforation. ${ }^{3}$ After several attempts to grasp the foreign body, endoscopists must consider more innovative options for the extraction of the RFB without iatrogenic injury. In this case, we initially used a Roth Net retriever to remove the golf ball. The size of the Roth Net retriever was smaller than that of the golf ball; furthermore, the golf ball was slippery, and the retriever was unable to grasp the ball completely. Subsequently, a stone extraction basket used for endoscopic retrograde cholangiopancreatography was used for the retrieval. The $30 \mathrm{~mm}$ stone extraction basket was pushed toward the rectal wall to increase the space between the wires, and the golf ball was inserted in the wire to hold it completely and tightly. Sometimes, placing the patient in a different position may be helpful to facilitate removal. As demonstrated in this case, using a stone extraction basket for removing RFBs is a safe and useful method. 

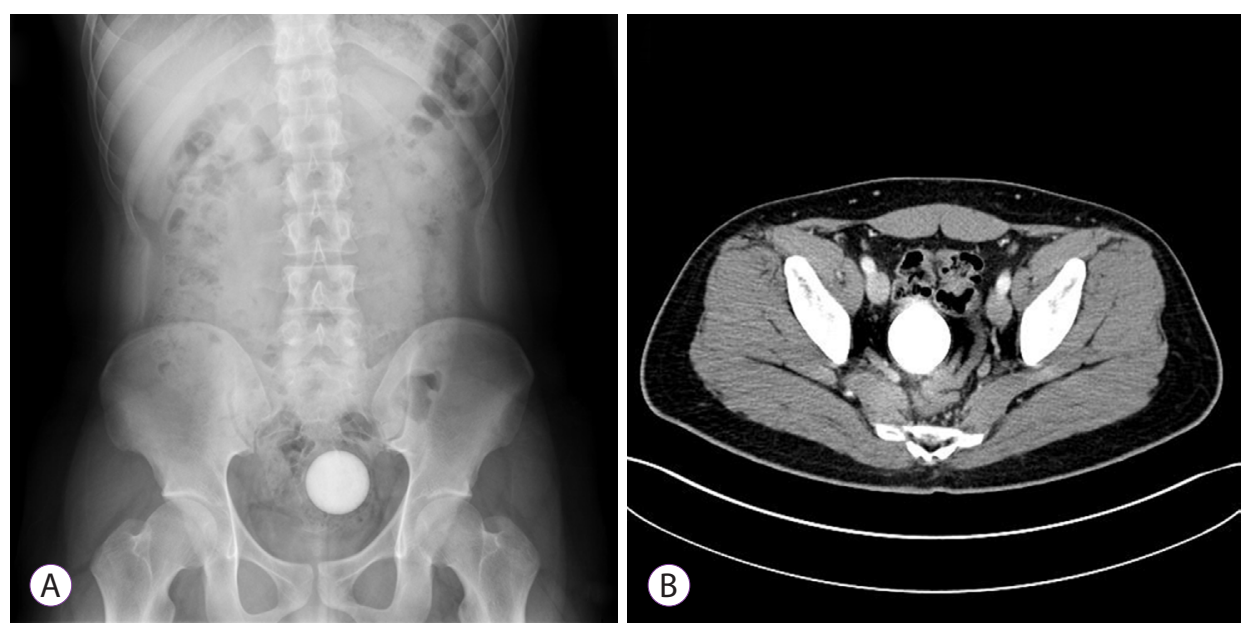

Fig. 1. (A) A plain pelvic/abdominal radiograph and (B) enhanced abdominopelvic computed tomography scan showing a $4.5-\mathrm{cm}$ round, opaque foreign body retained at the junction of the rectum and sigmoid, with no signs of perforation.
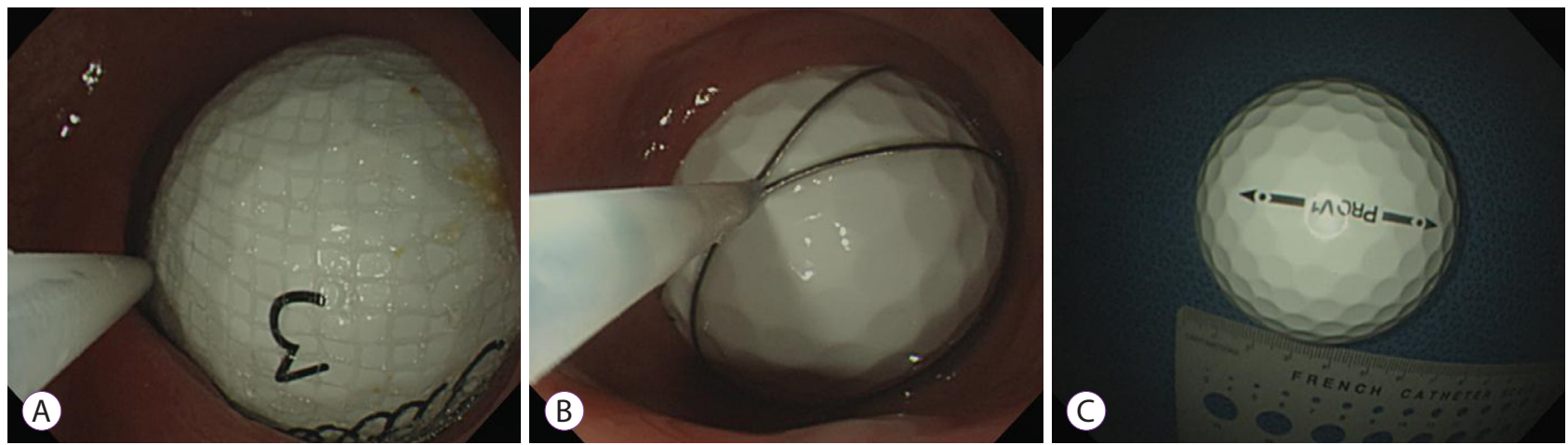

Fig. 2. (A) The use of a Roth Net retriever (US Endoscopy, Mentor, OH, USA) and (B) 30-mm stone extraction basket to remove the foreign body. (C) The extracted golf ball.

Conflicts of Interest

The authors have no potential conflicts of interest.

Funding

None.

Author Contributions

Conceptualization: Dong Hoon Baek

Supervision: Gwang Ha Kim, Geun Am Song

Writing-original draft: Young Joo Park

Writing-review\&editing: DHB, Eun Young Park

ORCID

Young Joo Park:

https://orcid.org/0000-0001-8416-0615
Dong Hoon Baek:

Eun Young Park:

Gwang Ha Kim:

Geun Am Song:

\section{REFERENCES}

1. Ayantunde AA. Approach to the diagnosis and management of retained rectal foreign bodies: clinical update. Tech Coloproctol 2013;17:13-20.

2. Ayantunde AA, Unluer $Z$. Increasing trend in retained rectal foreign bodies. World J Gastrointest Surg 2016;8:679-684.

3. Lake JP, Essani R, Petrone P, Kaiser AM, Asensio J, Beart RW Jr. Management of retained colorectal foreign bodies: predictors of operative intervention. Dis Colon Rectum 2004;47:1694-1698. 